Revista Brasileira de Agricultura Irrigada v.10, nº.5, p. 976 - 989, 2016

ISSN 1982-7679 (On-line)

Fortaleza, CE, INOVAGRI - http://www.inovagri.org.br

DOI: 10.7127/rbai.v10n500484

Protocolo 484.16 - 13/09/2016 Aprovado em 14/10/2016

\title{
PERCEPÇÃO DOS PRODUTORES RURAIS QUANTO AO USO DE AGROTÓXICOS
}

José Antônio de Sousa ${ }^{1}$, Hernandes de Oliveira Feitosa ${ }^{2}$, Clayton Moura de Carvalho ${ }^{3}$, Claudio Faustino Pereira ${ }^{4}$, Simone de Oliveira Feitosa ${ }^{5}$, Silvaneide Lobo da Silva ${ }^{5}$

\begin{abstract}
RESUMO
A utilização dos agrotóxicos no Brasil tem trazido sérias consequências, tanto para o meio ambiente como para a saúde do trabalhador rural. Assim, a presente pesquisa objetivou realizar um estudo exploratório afim de investigar se os produtores do Distrito de Cuncas no Município de Barro, Ceará, estão usando os agrotóxicos de forma correta. O trabalho de campo ocorreu nos meses de novembro/2014 e março e abril/2015, onde foi aplicado um questionário semiestruturado a 30 agricultores buscando coletar informações socioeconômicas (escolaridade), informações sobre o trabalho agrícola (área cultivada, principais culturas) e informações específicas sobre o uso de agrotóxicos (receituário agronômico, orientação para a manipulação, vestimentas usadas, opiniões sobre o uso de agrotóxicos). Constatou-se que a maior parte dos agricultores não entendem as informações no que diz respeito a bula e receituário agronômico, assim como não armazenam os agrotóxicos de forma correta, não usam equipamento de proteção ambiental e por isso alguns produtores estão contaminados. Concluise que os agricultores não usam os agrotóxicos de forma correta sendo passível de contaminação e consequente problemas de saúde.
\end{abstract}

Palavras-chave: defensivos agrícolas, contaminação, saúde pública.

\section{PERCEPTIONS OF FARMERS ON THE PESTICIDE USE}

\begin{abstract}
The use of pesticides in Brazil has brought serious consequences, both for the environment and for the health of rural workers. Thus, the present study aimed to carry out an exploratory study in order to investigate whether the producers of Cuncas District in Clay County, Ceará, are using pesticides correctly. Fieldwork took place in November/2014 and March and April/2015, which was applied a semi-structured questionnaire to 30 farmers seeking to collect

\footnotetext{
${ }^{1}$ Especialista em Agricultura Irrigada e Meio Ambiente, FATEC Cariri, e-mail: joseantoniosousa215@gmail.com

2 Doutor em Engenharia Agrícola, e-mail: hernandes.oliveira@gmail.com

${ }^{3}$ Doutor em Engenharia Agrícola, Prof. Colaborador do PRORH/UFS, e-mail: carvalho_cmc@ yahoo.com.br

${ }^{4}$ Graduando em Tecnologia de Irrigação e Drenagem, FATEC Cariri, e-mail: fclaudio051@ gmail.com

${ }^{5}$ Mestranda em Recursos Hídricos, UFS, e-mails: simone1929@outlook.com, silvaneide-123@ hotmail.com
} 
socioeconomic information (education), information on agricultural work (acreage, main crops) and specific information on the use of pesticides (agronomic prescription, guidance for handling, used clothing, opinions on the use of pesticides). It was found that most of the farmers do not understand the information regarding the label and agronomic prescription, and do not store pesticides properly, do not use environmental protection equipment and so some producers are contaminated. It is concluded that farmers do not use pesticides correctly and prone to contamination and consequent health problems.

Keywords: agrochemicals, contamination, public health.

\section{INTRODUÇÃO}

O efeito dos agrotóxicos no meio ambiente e na saúde das pessoas constitui assunto de grande importância, no sentido de que haja maiores estudos e pesquisas na parte prática de utilização dos agrotóxicos, bem como, prestação efetiva mais frequente dos serviços de assistência técnica por técnicos especializados no uso de agrotóxicos.

Os agrotóxicos são produtos constituídos de substâncias químicas, que tem a ação de eliminar pragas, patógenos causadores de doenças nas plantas cultivadas e também eliminar ervas daninhas, portanto eles são caracterizados em classes toxicológicas: altamente tóxicos, muito tóxicos, medianamente tóxicos e pouco tóxicos, assim sendo tornandose um dos maiores poluidores do meio ambiente, poluindo mais fortemente a água e o ar atmosférico, que são elementos indispensáveis à manutenção dos ecossistemas, podendo afirmar, sem eles não existiria vida no planeta terra (PERES; MOREIRA, 2003).

Os agrotóxicos foram estudados e são constituídos de moléculas químicas, formando os grupos químicos orgânicos e inorgânicos sintéticos, agrupando-se em grupo químico dos carbamatos, clorados, organofosforados e piretróides. Existem os inseticidas que atuam por contato e ingestão e os que têm ação sistêmicas, tendo o poder de penetrar na seiva das plantas, por isso sendo mais eficaz no controle das pragas (BAIRD, 2006; SILVA; FAY, 2004).

Segundo Peres e Moreira (2007), o Brasil figura entre os principais consumidores mundiais de agrotóxicos. Os dados a respeito de sua colocação no ranking desses consumidores são conflitantes e, portanto, imprecisos.
Já Porto e Soares (2012), afirmam que no início dos anos 1990, o Brasil já era o quinto mercado mundial, sendo que em 1994 e em 1998 atingiu a quarta e a terceira posições, respectivamente, apenas superado pelos EUA e pelo Japão. Atualmente o Brasil ocupa a posição de principal mercado consumidor de agrotóxicos do mundo (CASSAL et al., 2014).

Outra questão preocupante é que, apesar de se observar um crescimento exponencial do consumo de agrotóxicos nos últimos anos, as perspectivas de crescimento para o mercado no médio e longo prazo são ainda maiores (PORTO; SOARES, 2012).

Segundo Peres et al. (2005) e Monquero et al. (2009), a utilização dos agrotóxicos no meio rural brasileiro tem trazido uma série de consequências, tanto para o ambiente como para a saúde do trabalhador rural. Em geral, essas consequências são condicionadas por fatores intrinsecamente relacionados, tais como o uso inadequado dessas substâncias, a pressão exercida pela indústria e o comércio para esta utilização, a alta toxicidade de certos produtos, a ausência de informações sobre saúde e segurança de fácil apropriação por parte deste grupo de trabalhadores e a precariedade dos mecanismos de vigilância. Esse quadro é agravado por uma série de determinantes de ordem cultural, social e econômica (PERES et al., 2005).

Este é um trabalho de natureza exploratória e descritiva, que objetivou investigar a utilização dos agrotóxicos por parte dos agricultores do Distrito de Cuncas - Barro CE.

\section{MATERIAL E MÉTODOS}


O estudo desenvolveu-se no distrito de Cuncas no Município de Barro, situado na região Cariri, Sul do Estado do Ceará $\left(07^{\circ} 10^{\prime} 37^{\prime \prime}\right.$ $\mathrm{S}$ e $\left.38^{\circ} 46^{\prime} 55^{\prime \prime} \mathrm{O}\right)$. O município é muito importante na economia Cearense, devido as atividades da agricultura e da pecuária. Assim, a produção agrícola caracteriza-se por culturas anuais e pela criação de aves, suínos, bovinos e ovinos.

O trabalho de campo ocorreu nos meses de novembro/2014, março e abril/2015. Inicialmente, realizou-se entrevistas com informantes-chave de órgãos importantes na região, objetivando o levantamento de informações sobre a comunidade e o processo de trabalho. A partir desta etapa, elaborou-se um questionário semiestruturado.

Coletou-se informações socioeconômicas (escolaridade), informações sobre o trabalho agrícola (tamanho da área cultivada, principais culturas, destino da produção) e informações específicas sobre o uso de agrotóxicos (receituário agronômico, orientação para a manipulação, vestimentas usadas, opiniões sobre o uso de agrotóxicos, uso de equipamentos de proteção individual (EPI), episódios de intoxicação, etc.). A aplicação do questionário para cada agricultor teve o tempo médio de entrevistas entre 30 a 40 minutos.

A população do estudo constitui-se por trinta agricultores familiares adultos, que tem neste tipo de agricultura a sua fonte de subsistência, residentes no distrito de Cuncas,

A.

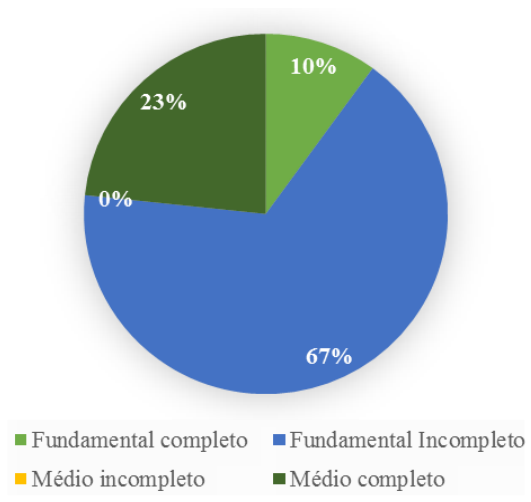

Barro, CE. Sendo a proposta metodológica com abordagem qualitativa, não foi previamente definido um plano amostral da população para aplicação dos questionários, formulados com perguntas abertas e fechadas (MINAYO; SANCHES, 1993; DESLANDES; ASSIS, 2003). A escolha dos informantes realizou-se de acordo com os pressupostos de diversidade de perfil. As variáveis analisadas para inclusão foram faixa etária, tempo de trabalho como agricultor, sexo, tamanho da propriedade e tipos de culturas produzidas.

Após a coleta dos dados os mesmos foram tabulados e analisados através de Microsoft Excel, versão 2013, para a confecção de tabelas e gráficos no âmbito de melhor interpretar as informações.

\section{RESULTADOS E DISCUSSÃO}

Os agricultores do distrito de Cuncas Barro - CE, responderam a um questionário abordando os aspectos relacionados ao uso de agrotóxicos. Dos 30 agricultores, 20 (67\%) afirmaram terem ensino fundamental incompleto, 7 (23\%) o ensino médio completo e apenas $3(10 \%)$ falaram que tem o fundamental completo como demonstra a Figura $1 \mathrm{~A}$. Observa-se que de todos os agricultores pesquisados nenhum é analfabeto, caracterizando assim que os agricultores entrevistados sabem ler.

B.

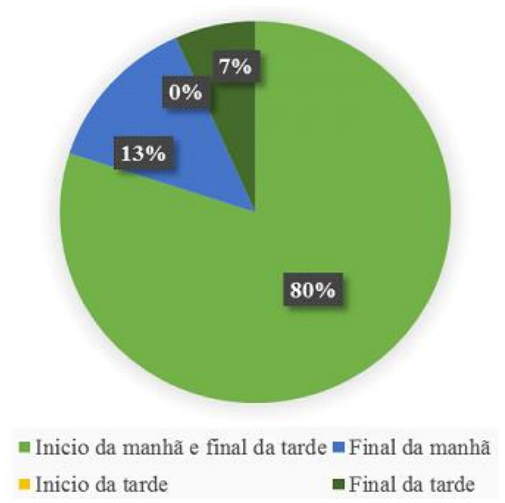

Figura 1. Nível de escolaridade dos agricultores e horário de aplicação de agrotóxicos.

Acredita-se certamente que muitos agricultores são contaminados muitas vezes por terem um nível educacional suficientemente baixo por não entender como e quais as formas 
que o agrotóxico pode afetar o ser humano. Neste sentido, Peres et al. (2001) e OliveiraSilva et al. (2001), relacionam o impacto da contaminação humana por agrotóxicos a fatores socioeconômicos, como o nível educacional, a habilidade de leitura e escrita e a renda familiar.

Isso é evidente quanto ao conhecimento sobre agrotóxico, pois, em um estudo das práticas relacionadas à aplicação de inseticida na cidade de Culturama (MT), Recena et al. (2008), verificaram que $97,2 \%$ dos entrevistados utilizaram a palavra veneno para descrever agrotóxicos, em vez de outros termos, como protetor de culturas ou pesticidas.

Na Figura 1B, constata-se o horário de aplicação dos agrotóxicos pelos os agricultores, verifica-se que $87 \%$ dos entrevistados sabem o horário correto de aplicar os agrotóxicos, $80 \%$ (período do início da manhã e final da tarde) e 7\% (início da manhã). Pode-se observar também que um percentual de $13 \%$ dos agricultores aplicam agrotóxicos em horário inadequado, nas horas mais quentes do dia.

Os maiores riscos de intoxicação estão relacionados ao contato do produto ou da calda com a pele. A via mais rápida de absorção é pelos pulmões; daí, a inalação constituir-se em grande fator de risco. Assim, os trabalhadores que aplicam rotineiramente agrotóxicos devem

A.

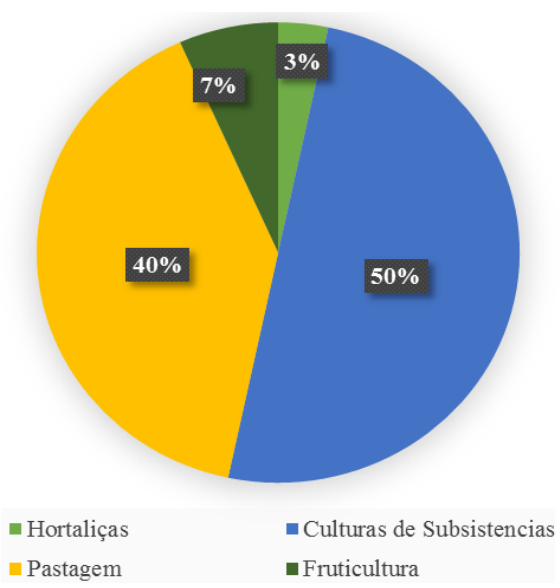

se submeter periodicamente a exames médicos (SOUZA, 2005).

A utilização de agrotóxicos é influenciada por diversos fatores, dentre os quais destacamse o clima, o hospedeiro, o alvo biológico, o ingrediente ativo e o veículo utilizado no produto. É aconselhável que as pulverizações com agrotóxicos sejam realizadas nas horas mais frescas do dia, ou seja, pela manhã e ao final da tarde, a fim de evitar a evaporação rápida do produto aplicado. Deve-se interromper a pulverização quando a velocidade do vento ultrapassar $3 \mathrm{~m} \mathrm{~s}^{-1}$ (as folhas das árvores começam a se agitar) (MATUO, 1990; GARRIDO, 2003).

Analisando a Figura 2, pode-se verificar as culturas exploradas pelos agricultores (Figura 2A), a quantidade de área cultivada (Figura 2B) e o produto colhido (Figura 2C). Portanto, percebe-se que $90 \%$ das áreas exploradas pelos agricultores são cultivadas com pastagem (40\%) e culturas de subsistências (50\%) como milho, feijão, fava, entre outras. Também, $43 \%$ dos entrevistados tem mais que 5 ha sendo explorado e um percentual de $37 \%$ com uma área menor que 2 ha. Quando questionados sobre os produtos colhidos, 62\% dos agricultores consomem e vendem, sendo maior parte (67\%) desse produto a nível de propriedade.

B.

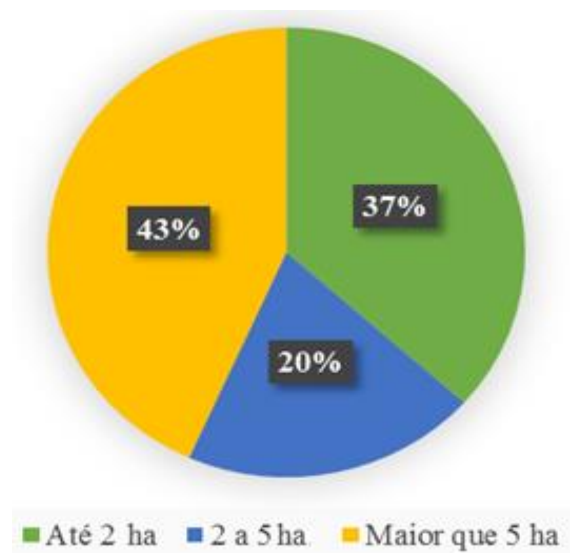


C.

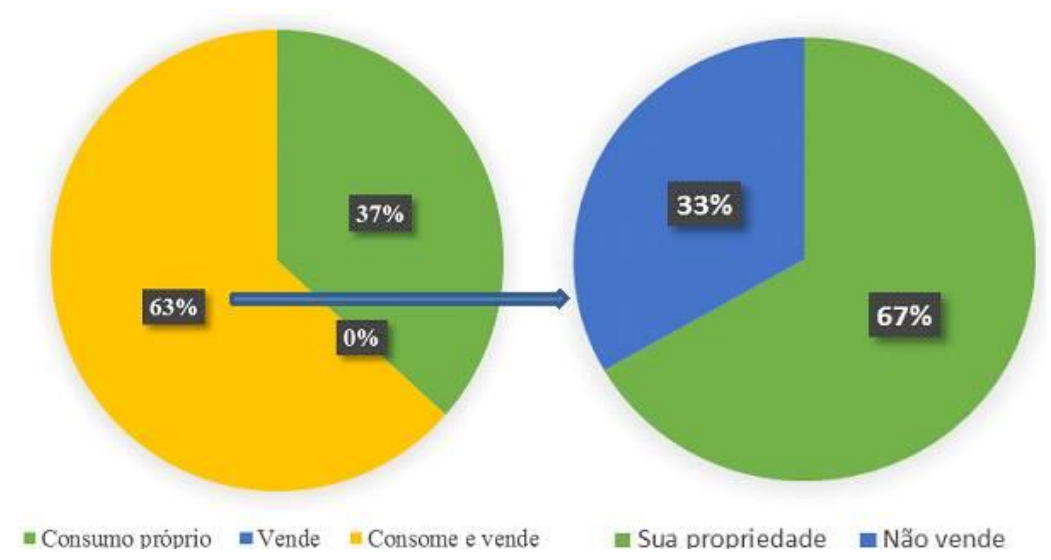

Figura 2. Culturas exploradas (A), área cultivada (B) e destinação do produto colhido dos agricultores (C).

Segundo Aventura et al. (2012), as técnicas de produção utilizadas pelos agricultores familiares ainda são, em sua maioria, rústicas, seja por costume ou por dificuldade de acesso às tecnologias. As melhorias tecnológicas estão intimamente ligadas ao acesso a créditos e a programas dos governos federais ou municipais; porém, investimentos em tecnologias, como assistência técnica, não são priorizados por estes produtores, muitas vezes, por falta de conhecimento sobre estas políticas públicas. Desta forma, estes pequenos agricultores ficam em desvantagem com os grandes produtores que possuem tanto acesso e incentivo à assistência técnica quanto às novas tecnologias.

A.

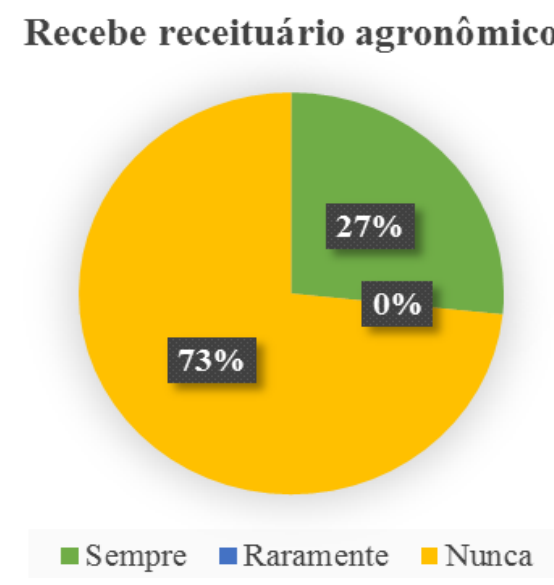

Quando questionados sobre o receituário agronômico, $73 \%$ afirmaram nunca terem recebido e apenas $27 \%$ falaram que sempre recebem (Figura 3). Porém, dos que recebem receituário, $90 \%$ declaram não seguir as orientações e $3 \%$ dizem que sempre seguem. Isso está relacionado, em parte, a compreensão das informações, pois, $53 \%$ afirmam que não compreendem o que está escrito e por isso não leem a bula e, acima de $50 \%$ dos produtores não entendem os desenhos nas embalagens, muito menos as tarjas. Também, do total de entrevistados, menos de $20 \%$ entendem essas informações tanto no receituário, na bula e nas embalagens, isso se respalda pelo seu nível educacional, que mesmo a maioria sabendo ler (alfabetizados), não entendem o que está escrito.

B.

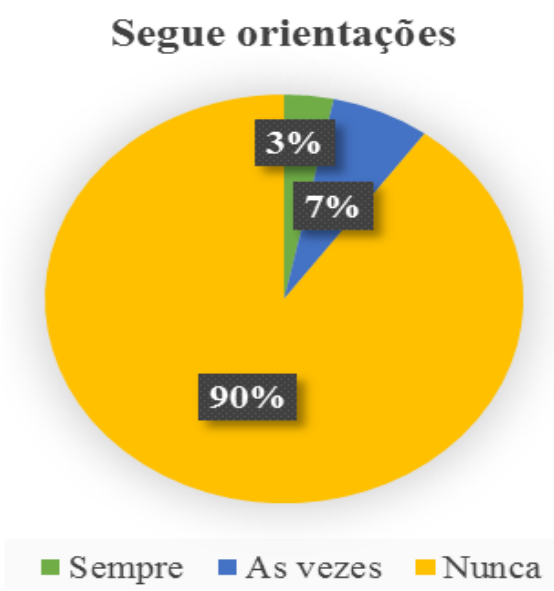


C.

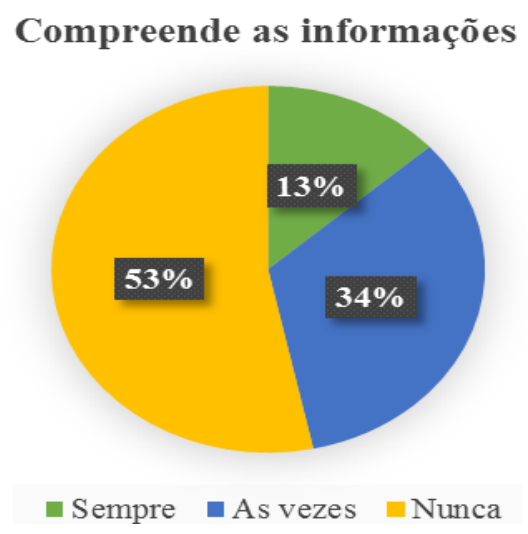

E.

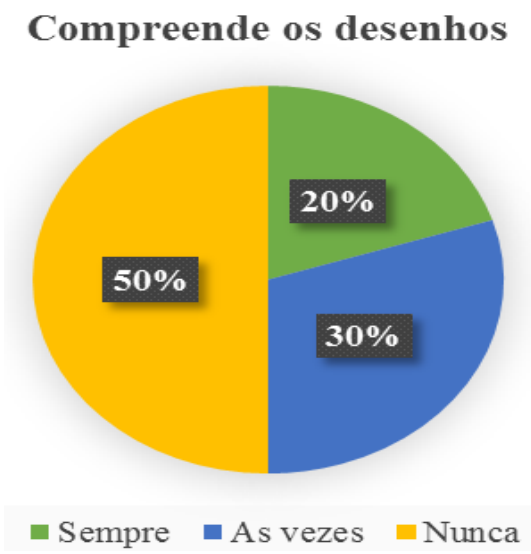

D.

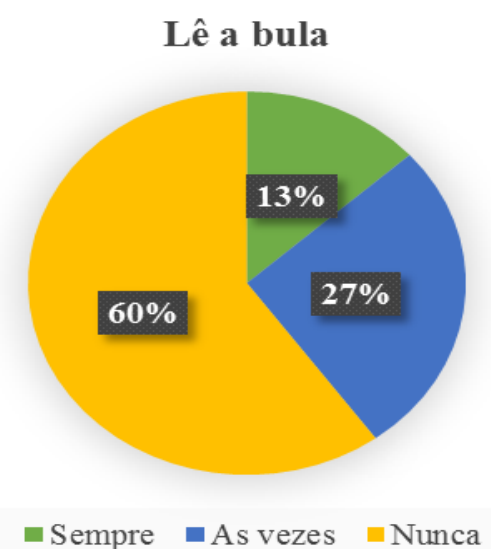

F.

Compreende as tarjas

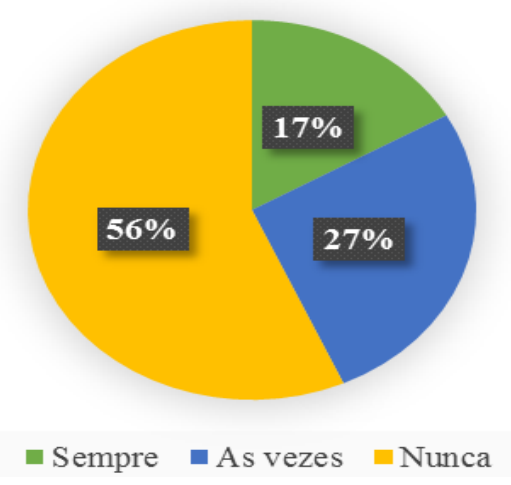

Figura 3. Fontes de orientações recebidas pelos agricultores sobre a utilização de agrotóxicos.

A informação sobre agrotóxicos, que no caso implica considerar os riscos ambientais e de saúde decorrentes do uso destes insumos na agricultura, pode ser considerada, portanto, como um dos determinantes para a construção de uma realidade menos prejudicial à saúde e ao meio ambiente (AYRES et al., 2003).

Com o tamanho da letra e com o excesso de informações técnicas contidas no rótulo e na bula, muitos agricultores confirmam que leem as informações relativas a pragas e dosagens, mas não sobre cuidados e segurança (CASTELO BRANCO, 2003; MARQUES et al., 2010). Sobre este fato, Peres et al. (2001) observaram, que a maioria das informações técnicas contidas em bulas e rótulos dos produtos formulados não é inteligível para o trabalhador rural.

De acordo com Marques et al. (2010), os principais motivos para a dificuldade de leitura e compreensão do conteúdo dos rótulos e bulas de agrotóxicos foram os termos técnicos utilizados e o tamanho reduzido das letras das informações. Já Oliveira-Silva et al. (2001), verificaram na condução do seu trabalho que $64 \%$ dos agricultores entrevistados no município de Magé (RJ) não praticavam a leitura dos rótulos dos produtos. Os autores atribuem estes resultados aos níveis de escolaridade aliados à linguagem técnica das informações contidas nas embalagens que justificam a deficiência na compreensão das informações pelos trabalhadores rurais. De maneira semelhante, Siqueira et al. (2008) consideram a linguagem pouco acessível como um entrave ao entendimento dos usuários.

A proteção através do uso de equipamentos/vestimentas para a manipulação de agrotóxicos é outra questão que descortina o alto grau de exposição de trabalhadores rurais. Na Figura 4, observa-se que em torno de $80 \%$ dos produtores não usam os equipamentos de proteção individual 


\section{PERCEPÇÃO DOS PRODUTORES RURAIS QUANTO AO USO DE AGROTÓXICOS}

como (botas e luvas de borracha, máscara com filtro, touca árabe, avental, calça, jaleco e viseira). Com isso constata-se que menos de

A.

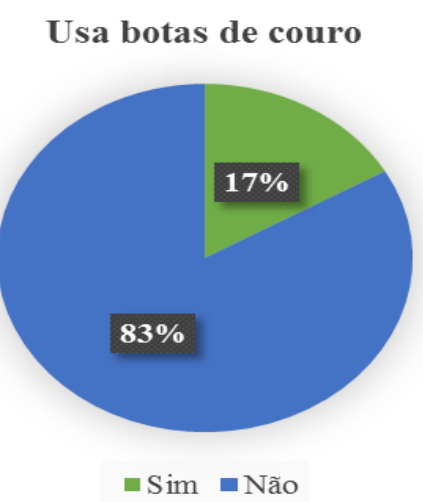

C.

Usa luvas de borracha

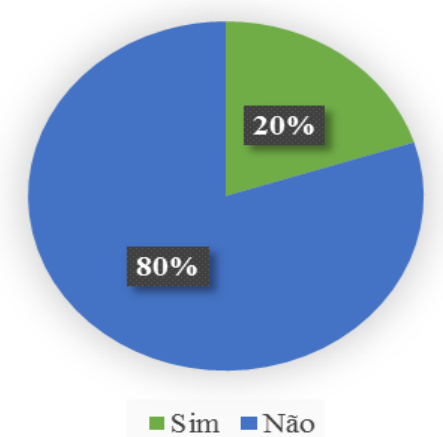

E.

Usa touca árabe

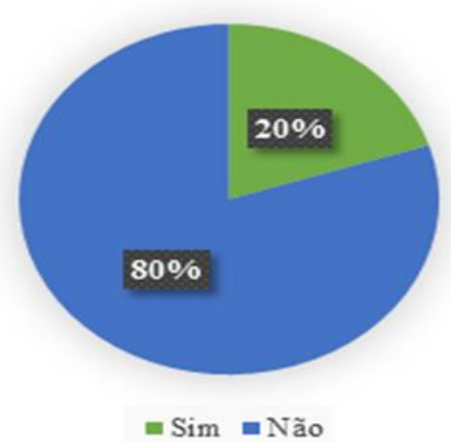

G.

Usa avental

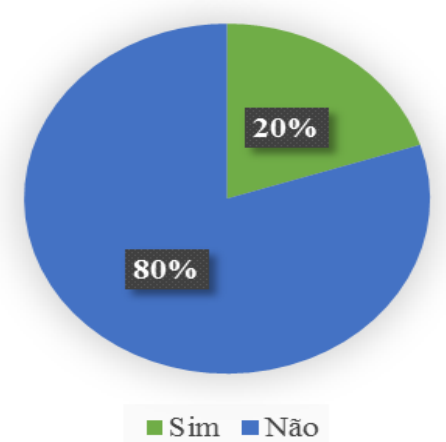

$20 \%$ dos agricultores usam o EPI, estando estes menos expostos a uma contaminação por agrotóxico.

B.

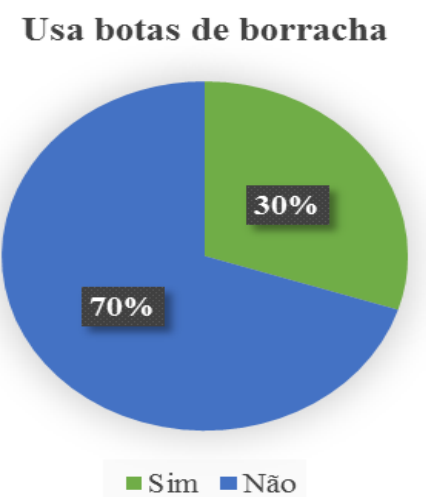

D.

\section{Usa máscara de filtro}

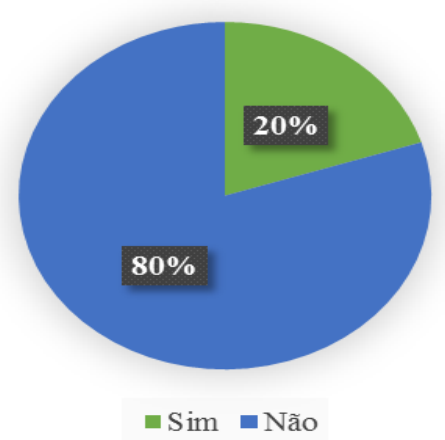

F.

Usa calça e jaleco

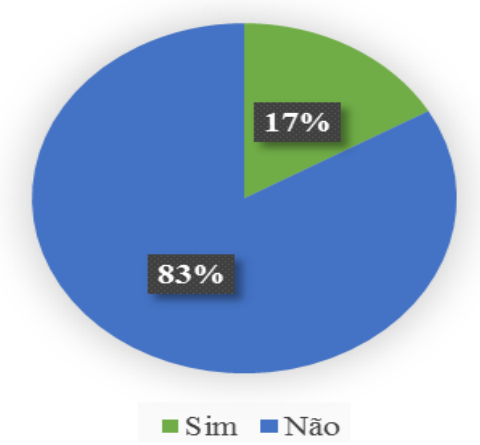

H.

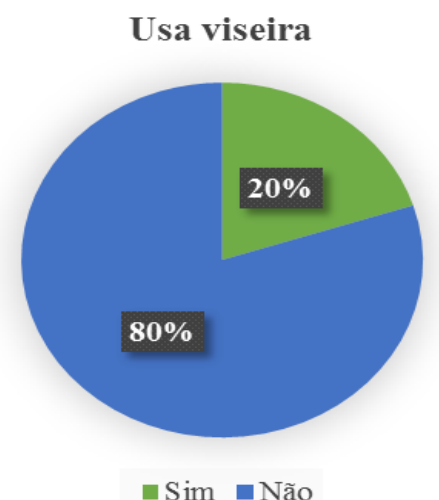

Figura 4. Relato dos agricultores sobre os equipamentos utilizados na hora da aplicação dos agrotóxicos. 
Os informantes, em sua maioria, reconhecem a importância do uso de proteção para lidar com agrotóxicos. Entretanto, esta é uma prática pouco frequente entre agricultores brasileiros e muito pode ser discutido neste sentido, incluindo o desconforto trazido pelo uso, a falta de recursos financeiros para adquirir o equipamento e também questões culturais.

Em conformidade ao exposto, Lima et al. (2015) afirma que os agricultores reclamam do desconforto dos EPIs devido as altas temperaturas do nosso clima semiárido, o que torna os equipamentos de proteção inadequados ao trabalho, além de ser mais um custo para o produtor.

É esperado que o uso de EPI possa minimizar a ocorrência de episódios de intoxicação, mas os extensos danos crônicos que o agrotóxico traz ao ambiente, à biodiversidade e ao próprio homem devem ser trabalhados através de uma mudança do paradigma na agricultura, que reduza e até mesmo um dia venha a excluir o uso destes químicos. Assim, o uso de EPI não deve ser o foco único de uma política de orientação ao agricultor que vise à redução dos riscos de contaminação (BRITO et al., 2009).

A.

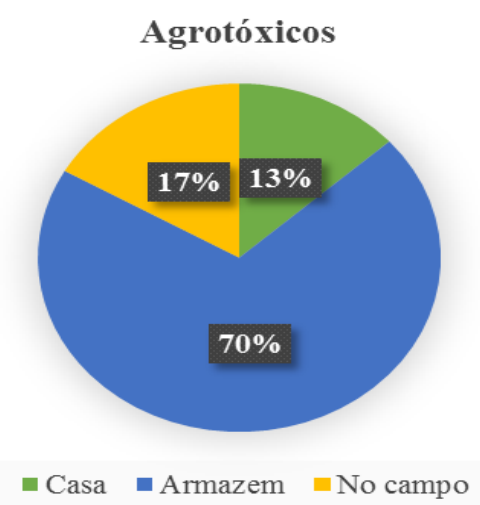

C.

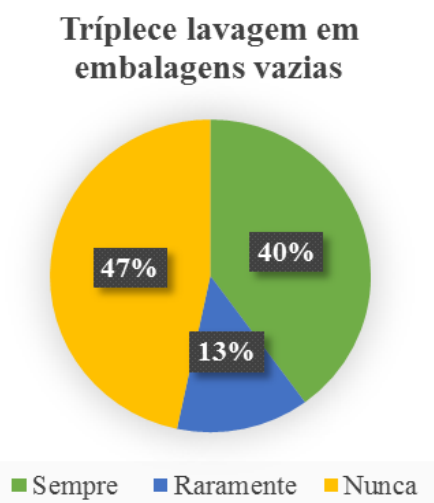

Também, é bastante frequente a falta de cuidados básicos para lidarem com os produtos. Dentre as variáveis para caracterizar a exposição exagerada aos agrotóxicos, o uso de equipamentos de proteção individual (EPI) e a ocorrência de intoxicações na população são bastante descritas por Moreira et al. (2002).

$\mathrm{Na}$ Figura 5, estão descritas as informações sobre $\mathrm{o}$ armazenamento dos agrotóxicos e das embalagens pelos produtores. Quando questionados, com relação ao armazenamento dos agrotóxicos (Figura 5A) $70 \%$ informam que deixam nos armazéns e 13\% guardam em casa e $17 \%$ armazenam no campo. Quanto as embalagens vazias (Figura 5B) após o uso, $57 \%$ jogam no terreno, ou seja, no campo a céu aberto, $33 \%$ deixa dentro do armazém, $10 \%$ armazenam no campo e nenhum armazena em casa. Perguntados sobre a tríplice lavagem nas embalagens (Figura 5C), 47\% afirmam nunca lavar os recipientes de agrotóxicos, já $40 \%$ dizem fazerem a tríplice lavagem. Porém, quanto ao pulverizador se faz a lavagem ou não (Figura 5D), 57\% dizem que lavam o pulverizador e um grande percentual (30\%) nunca lavam o pulverizador.

B.

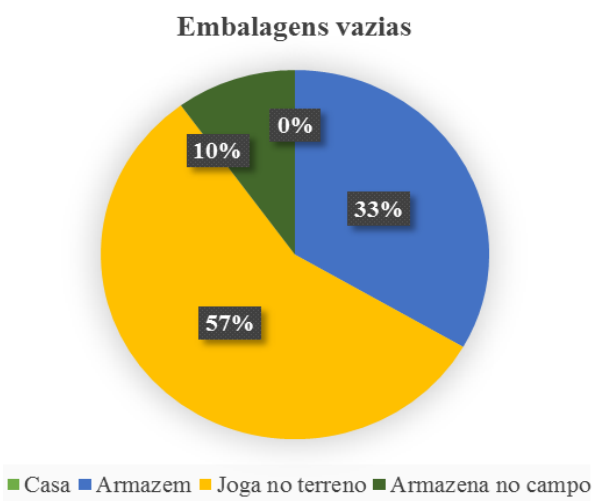

D.

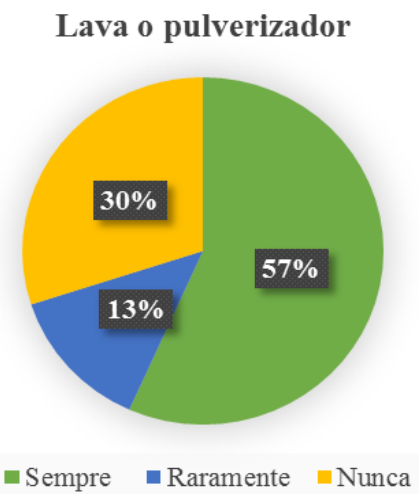




\section{PERCEPÇÃO DOS PRODUTORES RURAIS QUANTO AO USO DE AGROTÓXICOS}

E.

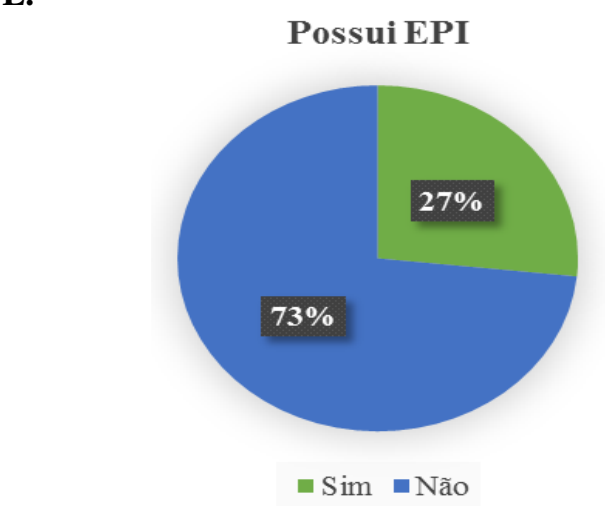

F.

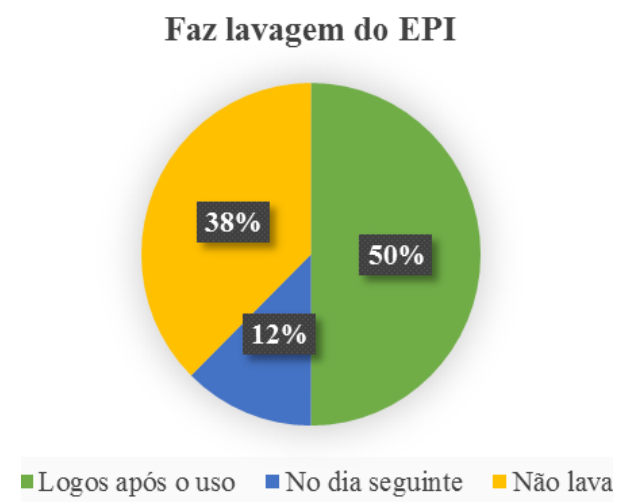

G

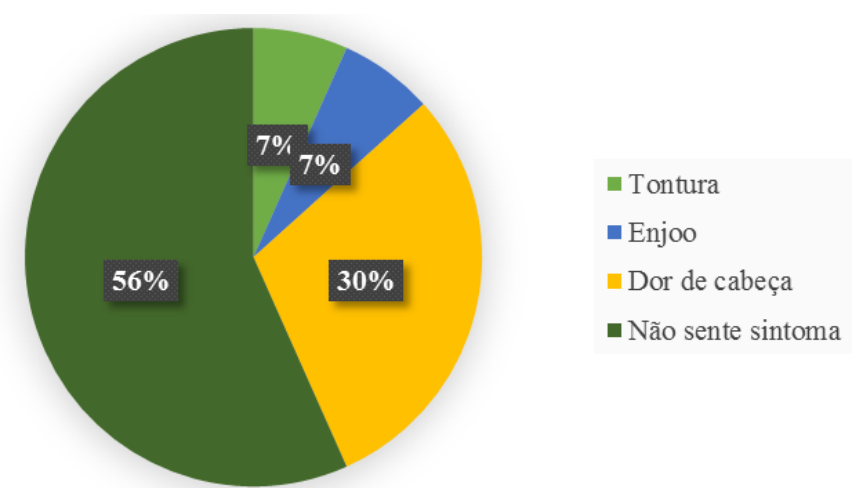

Figura 5. Relato dos agricultores sobre armazenagem e lavagem dos recipientes com agrotóxicos, aquisição e lavagem de EPI, e sintomas que sentem ao aplicar os agrotóxicos.

Um dos principais motivos e também preocupante, é a destinação final correta para as embalagens vazias dos agrotóxicos, e com isso diminuir o risco para a saúde das pessoas e de contaminação do meio ambiente. É um procedimento complexo, que envolve a todos, desde a fabricação, comercialização, utilização, licenciamento, fiscalização e também o monitoramento das atividades relacionadas com $\mathrm{o}$ manuseio, transporte, armazenamento correto (SOUZA CRUZ, 1998). Apesar de muitas vezes essas embalagens terem um destino ameaçador, tanto para o ser humano, quanto para a biodiversidade que o rodeiam, colocando em risco o planeta, e quem habita nele, é fácil encontrarmos embalagens ou frascos de agrotóxico jogados em córregos, estradas e até mesmo próximas às plantações.

Compete ao vendedor e distribuidor disponibilizar e gerenciar unidades de recebimento para a devolução de embalagens vazias pelos usuários (agricultores), e ao fabricante providenciar o recolhimento, e dar a destinação final adequada às embalagens vazias devolvidas as unidades de recebimento (SOUZA CRUZ, 1998).

As embalagens lavadas deverão ser armazenadas com as suas respectivas tampas e rótulos e, preferencialmente, acondicionadas na caixa de papelão original, em local coberto, ao abrigo de chuva, ventilado ou no próprio depósito de embalagens cheias. Nunca armazenar as embalagens, lavadas ou não, dentro de residências ou de alojamentos de pessoas ou animais, e também não armazenar as embalagens junto com pessoas, animais, medicamentos, alimentos ou rações. Deve-se certificar que as embalagens estejam adequadamente lavadas e com o fundo perfurado, evitando assim a sua reutilização (INPEV, 2002).

A Figura 5E representa o resultado sobre a aquisição de EPI e a Figura 5F o resultado sobre a sua lavagem. Assim, constata-se que $73 \%$ dos produtores não possuem EPI e apenas $27 \%$ possui esse equipamento para seu uso. Também, verifica-se que $50 \%$ dos entrevistados relatam que lavam o EPI logo após o uso, 12\% lavam no dia seguinte e $38 \%$ dizem que nunca lavam. Um 
dos fatores limitantes a não aquisição do EPI é o preço que, por muitas vezes, está acima do orçamento dos produtores, acreditando-se também, que há falta de uma política agrícola que enfatize a importância da segurança.

Em estudos anteriores a este, valores similares foram observados para produtores de fumo $(74,4 \%)$ que também não utilizavam nenhum tipo de EPI durante as aplicações de agrotóxicos. Isto foi constatado em entrevistas realizadas por Agostinetto et al. (1998) no município de Pelotas, Rio Grande do Sul. Delgado e Paumgartten (2004) ao entrevistarem 52 agricultores do município de Paty do Alferes, Rio de Janeiro, verificaram que $92 \%$ dos entrevistados não faziam uso EPIs durante a preparação e aplicação das caldas.

Recena et al. (2008) relacionaram a intoxicação dos agricultores, não só à ausência de equipamentos de proteção individual e à toxidade dos produtos, mas também às práticas de baixa tecnologia. Segundo Silva et al. (2001), o despreparo da população para a manipulação destas substâncias e a falta de apoio técnico contribuem para a exposição da população aos pesticidas.

Na Figura 5G verifica-se que dentre os produtores entrevistados $56 \%$ informam não sentir sintomas durante e/ou após a aplicação de agrotóxicos, já 30\% afirmam sentir dor de cabeça, $7 \%$ apresenta tontura e 7\% enjoo, mesmo aplicando nos horários indicados (início da manhã ou final da tarde). Isso demonstra o grau de toxidez, da aplicação errada, sem uso de EPI e da classe toxicológica do agrotóxico.

Peres et al. (2004) ressaltam que, segundo entrevistados, os principais sintomas de intoxicação são dor de cabeça, dor de barriga e tontura. Pires et al. (2005) relacionam ainda as atividades agrícolas às intoxicações e tentativas de suicídio pela exposição a agrotóxicos na microrregião de Dourados (MS), principalmente durante a safra de verão.

De acordo com a Tabela 1, observa-se que diante dos 31 agrotóxicos mais citados pelos agricultores do distrito de Cuncas, 55\% desses agrotóxicos são inseticidas, $26 \%$ fungicidas e $19 \%$ herbicidas. Consta-se ainda que $68 \%$ dos agrotóxicos utilizados pelos agricultores são de tarjas vermelha e amarela, ou seja, apresenta grau altamente tóxico, enquanto que, nenhum dos agrotóxicos usados apresentam tarja verde com classe de pouco tóxico. Maior parte desses agrotóxicos são utilizados em culturas como tomate, pimentão e em pastagens.

Tabela 1. Agrotóxicos utilizados pelos agricultores de Cuncas, Barro-CE.

\begin{tabular}{|c|c|c|c|}
\hline Inseticida & $\begin{array}{c}\text { Concentração } \\
\text { I.a. }\end{array}$ & $\begin{array}{c}\text { Classe } \\
\text { Toxicológica } \\
\end{array}$ & Ingrediente ativo \\
\hline Agritoato 400 & 400 & I & Dimetoato \\
\hline Cartap br 500 & 500 & III & Cloridrato de cartape \\
\hline Connect & $100+12,5$ & II & Imidacloprido + beta-ciflutrina \\
\hline Decis $25 \mathrm{ec}$ & 25 & III & Deltametrina \\
\hline Deltaphos EC & $1,0+350$ & I & (Deltametrina + triazofós \\
\hline Fastac 100 & 100 & II & Alfa-cipermetrina \\
\hline Folisuper $600 \mathrm{br}$ & 600 & I & Parationa metilica \\
\hline Lannate br & 215 & I & Metomil \\
\hline Mospilan & 200 & III & Acetamiprido \\
\hline Nuprid $700 \mathrm{wg}$ & 700 & III & Imidacloprido \\
\hline Oberon & 240 & III & Espiromesifeno \\
\hline Pirate & 240 & III & Clorfenapir \\
\hline Polytrin & $400+40$ & III & Profenofós + cipermetrina \\
\hline Premio & 200 & III & Clorantraniliprole \\
\hline Rotamik & 18 & I & Abamectina \\
\hline Thiobel 500 & 500 & III & Cloridrato de cartape \\
\hline Tiger $100 \mathrm{ec}$ & 100 & I & Piriproxifem \\
\hline Turbo & 50 & II & Beta ciflutrina \\
\hline Vertimec $18 \mathrm{EC}$ & 18 & III & Abamectina \\
\hline
\end{tabular}




\begin{tabular}{lccl}
\hline & I.a. & Toxicológica & \\
\hline Auge & 537,44 & III & Hidróxido de cobre \\
Cercobin $500 \mathrm{sc}$ & 500 & II & Tiofanato metilico \\
Dacobre wp & $200+300$ & II & Clorotalonil+oxicloreto de cobre \\
Galben-m & $80+650$ & I & Benalaxil + mancozeb \\
Kasumin & 20 & III & Casugamicina \\
Score & 250 & I & Difenoconazol \\
Sumilex 500 wp & 500 & II & Procimidona \\
Zetanil & $50+375$ & I & Cimoxanil + clorotalonil \\
\hline \multicolumn{1}{c}{ Herbicida } & Concentração & Classe & \multicolumn{1}{c}{ Ingrediente ativo } \\
Glifosato 480 agripec & I.a. & Toxicológica & \\
Gramoxone 200 & 480 & I & Glifosato \\
Grazon & 200 & I & Dicloreto de paraquate \\
Podium ew & $150,81+15,09$ & I & 2,4 d + picloram \\
Sencor 480 & 110 & I & Fenoxaprope-p-etílico \\
Tordon & 480 & II & Metribuzim \\
\hline
\end{tabular}

Classe I - extremamente tóxica (faixa vermelha), Classe II - altamente tóxica (faixa amarela), Classe III - medianamente tóxica (faixa azul) e Classe IV - pouco tóxica (faixa verde).

Segundo Silva et al. (2011) qualquer que seja o caminho do agrotóxico no meio ambiente, invariavelmente, o homem é seu potencial receptor, pois a maior parte dos agrotóxicos utilizados, independente do modo de aplicação, acaba atingindo o solo $\mathrm{e}$ as águas, principalmente devido aos ventos e à água das chuvas, que promovem a deriva, a lavagem das folhas tratadas, a lixiviação e a erosão.

Castro e Confalonieri (2005) realizaram um levantamento de propriedades rurais de Cachoeiras de Macacu (RJ) acerca da percepção de risco e das práticas de uso dos agrotóxicos e, pela análise dos resultados concluíram que $22,5 \%$ dos agricultores reportaram já terem sido intoxicados por agrotóxico, sendo o inseticida Decis 25 CE e o herbicida Gramoxone (ambos extremamente tóxicos) os mais utilizados na região.

Segundo Bedor et al. (2009), a falta de fiscalização no acompanhamento técnico e no controle de agrotóxicos faz com que a tomada de decisão do agricultor seja baseada apenas na produtividade, sem levar em conta outros fatores, relativos à saúde e ao meio ambiente.

\section{CONCLUSÕES}

Por meio deste estudo verificou-se uma série de problemas relacionados ao uso de agrotóxicos, mostrando a falta de conhecimento por parte dos agricultores de normas e cuidados mínimos necessários para o manuseio dos produtos químicos.

Os casos de intoxicação mostram o perigo representado pelos defensivos agrícolas à saúde dos agricultores e habitantes do meio rural, necessitando assim, o esclarecimento aos agricultores sobre o uso correto de EPI através de cursos, dias de campo, palestras, buscando a conscientização em relação ao risco de exposição de pessoas e animais aos agrotóxicos e seus efeitos no ambiente.

Os principais fatores responsáveis pelos riscos de intoxicação e de contaminação do meio ambiente é a falta de uma política mais efetiva de fiscalização, controle e acompanhamento técnico adequado na utilização de agrotóxicos, sendo assim, seriam necessárias medidas urgentes por partes de órgãos governamentais, empresas produtoras de agrotóxicos e a sociedade em geral, buscando reduzir impactos em relação ao meio ambiente e à saúde humana.

\section{REFERENCIAS}

AGOSTINETTO, D.; PUCHALSKI, L. E. A.; AZEVEDO, R.; STORCH, G.; BEZERRA, A. J. A.; GRÜTZMACHER, A. D. Utilização de equipamentos de proteção individual e intoxicações por agrotóxicos entre fumicultores do município de Pelotas-RS. Pesticidas Revista 
Ecotoxicologia e Meio Ambiente, v.8, p.45-56, 1998.

AVENTURA, T. M.; KARAMOTO F. A.; VIEIRA, F. P.; GUIMARÃES, G. M. A.; VIEIRA, T. R. A importância da diversificação da produção na agricultura familiar. In: simpósio sobre reforma agrária e questões rurais, 5, 2012, Araraquara. Anais eletrônicos... Araraquara: Unesp, 2012. 1cd-rom.

AYRES, J. R. C. M.; JÚNIOR, I. F.; CALAZANS, G. J.; FILHO, H. C. S. O conceito de vulnerabilidade e as práticas de saúde: novas perspectivas e desafios. In: CZERESNIA, D.; FREITAS, C. M. (Org). Promoção da saúde: conceitos, reflexões, tendências. Rio de Janeiro: Fiocruz, 2003. p.117-139.

BAIRD, C. Chemistry in your life. 2. ed. New York: W. H. Freeman, 2006.

BEDOR, C. N. G.; RAMOS, L. O.; PEREIRA, P. J.; RÊGO, M. A. V.; PAVÃO, A. C.; AUGUSTO, L. G. S. Vulnerabilidades e situações de riscos relacionados ao uso de agrotóxicos na fruticultura irrigada. São Paulo: Rev. bras. Epidemiol. v.12, n.1, p.39-49, 2009.

BRASIL. FUNDAÇÃO OSWALDO CRUZ. SISTEMA NACIONAL DE INFORMAÇÃO TÓXICOFARMACOLÓGICA. Estatística anual de casos de intoxicação e envenenamento. Rio de Janeiro, 1993. 74p.

BRITO, P. F.; GOMIDE, M.; CÂMARA, V. M. Agrotóxicos e saúde: realidade e desafios para mudança de práticas na agricultura. Physis Revista de Saúde Coletiva, v.19, n.1, p.207225, 2009.

CASSAL, V. B.; AZEVEDO, L. F. de; FERREIRA, R. P.; SILVA, D. G. da; SIMÃO, R. S. Agrotóxicos: uma revisão de suas consequências para a saúde pública. Revista Eletrônica em Gestão, Educação e Tecnologia Ambiental - REGET, v.18, n.1, p.437-445, 2014.
CASTELO BRANCO, M. Avaliação do conhecimento do rótulo dos inseticidas por agricultores em uma área agrícola do Distrito Federal. Horticultura Brasileira, v.21, n.3, p.570-573, 2003.

CASTRO, J. S. M.; CONFALONIERI, U. Uso de agrotóxicos no Município de Cachoeiras de Macacu (RJ). Ciênc. saúde coletiva, v.10, n.2, p.473-482, 2005.

DELGADO, I. F.; PAUMGARTTEN, F. J. R. Intoxicações e usos de pesticidas por agricultores do Município de Paty do Alferes, Rio de Janeiro, Brasil. Caderno de Saúde Pública, v.20, n.1, p.180-185, 2004.

DESLANDES, S. F.; ASSIS, S. G. Abordagens quantitativa e qualitativa em saúde: o diálogo das diferenças. In: MINAYO M. C. S., DESLANDES S. F. (orgs.). Caminhos do pensamento: epistemologia e método. Rio de Janeiro: Fiocruz, 2003. p. 195-223.

GARRIDO, L. R. Sistema de produção de pêssego de mesa na região da Serra Gaúcha: tecnologia de aplicação de agrotóxicos. Bento Gonçalves: Embrapa Uva e Vinho, 2003. (Sistema de Produção, 3). CD-ROM

INPEV (INSTITUTO NACIONAL DE PROCESSAMENTO DE EMBALAGENS VAZIAS). Destinação final de embalagens vazias de agrotóxicos. São Paulo, 2002. 24p. (Manual de Orientação).

LIMA, L. B.; CARVALHO, C. M.; FEITOSA, H. O.; BITU, P. G. Uso de agroquímicos na produção de hortaliças em Farias Brito - CE. Brazilian Journal of Applied Technology for Agricultural Science, v.8, n.3, p.87-92, 2015.

MARQUES, C. R. G.; NEVES, P. M. O. J.; VENTURA, M. U. Diagnóstico do conhecimento de informações básicas para o uso de agrotóxicos por produtores de hortaliças da Região de Londrina. Semina: Ciências Agrárias, v.31, n.3, p.547-556, 2010. 
MATUO, T. Técnicas de aplicação de defensivos. Jaboticabal: Funep, 1990. 139p.

MINAYO M. C. M.; SANCHES O. Quantitativo-qualitativo: oposição ou complementaridade. Cad Saúde Pública, v.9, n.3, p.239-262, 1993.

MONQUERO, P. A.; INÁCIO, E. M.; SILVA, A. C. Levantamento de agrotóxicos e utilização de equipamento de proteção individual entre os agricultores da região de araras. Arq. Inst. Biol., v.76, n.1, p.135-139, 2009.

MOREIRA, J. C.; JACOB, S. C.; PERES, F.; LIMA, J. S.; MEYER, A.; OLIVEIRA-SILVA, J.J.; SARCINELLI, P. N.; BATISTA，D.F.; EGLER, M.; FARIA, M. C. F.; ARAÚJO, A. J.; KUBOTA, A. H.; SOARES, M. O.; ALVES, S. R.; MOURA, C. M.; CURI, R. Avaliação integrada do impacto do uso de agrotóxicos sobre a saúde humana em uma comunidade agrícola de Nova Friburgo, RJ. Ciência \& Saúde Coletiva, v.7, n.2, p.299-311, 2002.

OLIVEIRA-SILVA， J. J.; ALVES， S. R.; MEYER, A.; PEREZ, F.; SARCINELLI, P. N.; MATTOS, R. C. O. C.; MOREIRA, J. C. Influência de fatores socioeconômicos na contaminação por agrotóxicos, Brasil. Revista de Saúde Pública, v.35, n.2, p.130-135, 2001.

PERES, F. CUNHA, D; SILVA, A. R. Percepção das condições de trabalho em uma tradicional comunidade agrícola em Boa Esperança, Nova Friburgo, Rio de Janeiro, Brasil. Cad Saúde Pública, v.20, n.4, p.10591068, 2004.

PERES, F.; MOREIRA, J. C. (org.). É veneno ou é remédio? Agrotóxicos, saúde e ambiente. Rio de Janeiro: Fiocruz, 2003.

PERES, F.; MOREIRA, J. C. Saúde e ambiente em sua relação com o consumo de agrotóxicos em um pólo agrícola do Estado do Rio de Janeiro, Brasil. Cad. Saúde Pública, v.23, Suplemento 4, p.S612-S621, 2007.

PERES, F.; OLIVEIRA-SILVA, J. J.; DELLAROSA, H. V.; LUCA, S. R. Desafios ao estudo da contaminação humana e ambiental por agrotóxicos. Ciências e Saúde Coletiva, v.10, Suplemento, p.27-37, 2005.

PERES, F.; ROZEMBERG, B., ALVES, S. R.; MOREIRA, J. C.; OLIVEIRA-SILVA, J. J.. Comunicação relacionada ao uso de agrotóxicos em região agrícola do Estado do Rio de Janeiro. Rev. Saúde Pública, v.35, n.6, p.564-570, 2001.

PIRES, D. X.; CALDAS, E. D.; RECENA, M. C. P. Uso de agrotóxicos e suicídios no Estado do Mato Grosso do Sul, Brasil. Cad Saúde Pública, v.21, n.2, p.598-605, 2005.

PORTO, M. F.; SOARES, W. L. Modelo de desenvolvimento, agrotóxicos e saúde: um panorama da realidade agrícola brasileira e propostas para uma agenda de pesquisa inovadora. Revista Brasileira de Saúde Ocupacional, v.37, n.125, p.17-31, 2012.

RECENA, M. C. P.; CALDAS, E. D. Percepção de risco, atitudes e práticas no uso de agrotóxicos entre agricultores de Culturama, MS. Revista de Saúde Pública, v.42, n.2. p.294-391, 2008.

SILVA, C. M. M.; FAY, E. F. Agrotóxicos e ambiente. Brasília: Embrapa Informação Tecnológica, 2004.

SILVA, J. J. O.; ALVES, S. R.; MEYER, A.; PEREZ, F.; SARCINELLI, P. N.; MATTOS, R.; C. C., MOREIRA, J. C. Influência de fatores socioeconômicos na contaminação por agrotóxicos. Revista Saúde Pública, v.35, n.2, p. 130-135, 2001.

SILVA,L. M. F.; ARAÚJO, G. T.; SILVA, A. D. V.; VALNIR JÚNIOR, M.; CARVALHO, C. M. Levantamento dos agrotóxicos utilizados na horticultura no município de Ubajara - CE. Revista Brasileira de Agricultura Irrigada, v.5, n.4, p.280-285, 2011.

SIQUEIRA, S.L.; KRUSE, M.H.L. Agrotóxicos e saúde humana: contribuição dos profissionais do campo da saúde. Revista da Escola Enfermagem, v.42, n.3, p.584- 590, 2008. 
Sousa et al.

SOUZA CRUZ. Agrotóxicos - uso e cuidados. Florianópolis, 1989.

SOUZA, R. T. Sistema de Produção de Uvas Rústicas para Processamento em Regiões Tropicais do Brasil: normas gerais sobre o uso de agrotóxicos. Bento Gonçalves: Embrapa Uva e Vinho, 2005. (Sistema de Produção, 9). CD-ROM 